University of Nebraska - Lincoln

DigitalCommons@University of Nebraska - Lincoln

1975

\title{
The Effect of Cyclic Differential Stress on Dilatancy in Westerly Granite Under Uniaxial and Triaxial Conditions
}

Mark D. Zoback

U.S. Geological Survey, zoback@stanford.edu

James D. Byerlee

Stanford University

Follow this and additional works at: https://digitalcommons.unl.edu/usgsstaffpub

Part of the Earth Sciences Commons

Zoback, Mark D. and Byerlee, James D., "The Effect of Cyclic Differential Stress on Dilatancy in Westerly Granite Under Uniaxial and Triaxial Conditions" (1975). USGS Staff -- Published Research. 450.

https://digitalcommons.unl.edu/usgsstaffpub/450

This Article is brought to you for free and open access by the US Geological Survey at DigitalCommons@University of Nebraska - Lincoln. It has been accepted for inclusion in USGS Staff -- Published Research by an authorized administrator of DigitalCommons@University of Nebraska - Lincoln. 


\title{
The Effect of Cyclic Differential Stress on Dilatancy in Westerly Granite Under Uniaxial and Triaxial Conditions
}

\author{
Mark D. Zoback and James D. Byerlee \\ U.S. Geological Survey, Menlo Park, California 94025 \\ Department of Geophysics, Stanford University. Stanford, California 94305
}

\begin{abstract}
Laboratory experiments have been performed on samples of Westerly granite in which the differential stress was repeatedly cycled to $85 \%$ of the intact sample strength. The experiments have shown that under uniaxial conditions the onset of dilatancy is reduced to fairly low stress; however, under triaxial conditions dilatancy can be an apparently stable process, and the onset of dilatancy is not affected by the repeated cycling. Thus the implication for midcrustal earthquakes is that the onset of dilatancy repeatedly occurs at relatively high stress levels. For example, our results indicate that at typical focal depths of 2.5 and $10 \mathrm{~km}$ (corresponding to effective hydrostatic pressures of about 500 and 2000 bars) the onset of dilatancy repeatedly occurs at 1.8 and 3.0 kbar of differential compressive stress, respectively.
\end{abstract}

\section{INTRODUCTION}

An important assumption of the dilatancy-diffusion hypothesis of earthquake prediction [Nur, 1972; Scholz et al., 1973] is that materials in active fault zones can repeatedly dilate. That is, under the conditions of high tectonic stress preceding a given earthquake, dilatancy is assumed to occur despite the repeated occurrence of very large stresses throughout geologic history.

The purpose of this work was primarily to answer two important questions: Does dilatancy occur after many cycles of compressive stress? and if so, Is the onset of dilatancy significantly reduced by the repeated cycling?

Scholz and Kranz [1974] and Haimson [1974] reported the effects of cyclic loading on dilatancy in Westerly granite. However, the experiments of Scholz and Kranz were performed only under uniaxial conditions, and the experiments of Haimson were performed at very low confining pressure ( 70 bars) and very high loading rates.

\section{Results}

In these experiments the samples were axially loaded to about $85 \%$ of the intact sample strength and loaded and unloaded at a constant strain rate of $10^{-5} \mathrm{~s}^{-1}$. The intact sample strength of Westerly granite at the different confining pressures was reported by Mogi [1966].

Volumetric strain was measured in the manner described by Brace et al. [1966]. Axial and circumferential strain gages were attached directly to the sample for the uniaxial experiments and were attached to a thin copper jacket for the triaxial experiments. Volumetric strain was calculated from the individual strains $\left(\Delta v / v=\epsilon_{z}+2 \epsilon_{\theta}\right)$.

Figure 1 presents volumetric strain (compression is positive) as a function of differential stress under uniaxial conditions and under both 500 bars and 2000 bars of hydrostatic confining pressure. The values for volumetric strain are given in relation to the sample volume before applying either confining pressure or load. Only the first, second, and sixth full cycles of the uniaxial experiment are shown (Figure 1a); on the seventh cycle the sample failed at $81 \%$ of the intact sample strength. At 500 bars of confining pressure the experiment was terminated after 20 cycles; the first, second, fifth, tenth, and twentieth cycles are shown (Figure 1b). At 2000 bars the first,

Copyright $(c) 1975$ by the American Geophysical Union. second, and fifth cycles are shown; this experiment terminated with a jacket leak during the sixth cycle.

Following each cycle in Figure 1 the differential stress-volumetric strain loops did not completely return to their initial value, but rather the samples grew larger. Increased sample size results especially in the uniaxial sample, whereas under 500 or 2000 bars of confining pressure, significant permanent volume increase occurred only during the first cycle. From previous experiments it appears that significant permanent volume increase under triaxial conditions occurs only when the maximum differential stress exceeds the previously applied maximum differential stress or when the sample is subjected to high differential stress for a substantial period of time [Zoback and Byerlee, 1975].

At both 500 bars and 2000 bars of confining pressure the samples deform in a stable and repeatable manner. Figures $1 b$ and $l c$ show that the size of the differential stress-volumetric strain loops continuously decreases, approaching a steady state size. At 500 bars the loop size of the twentieth cycle is just slightly smaller than that of the fifteenth cycle. At 2000 bars the loop size of the fifth cycle is only slightly smaller than that of the fourth cycle.

Further illustration of the stable behavior of the triaxial samples (as well as the unstable behavior of the uniaxial sample) is presented in Figure 2. Under 500 and 2000 bars of confining pressure (Figures $2 b$ and $2 c$ ) the size of the differential stress-strain loops decreases for both the axial and the radial component of strain. However, in Figure $2 a$ (the uniaxial sample) note that between cycles 1,3 , and 6 the size of the differential stress-axial strain loop uniformly decreases, whereas the size of the differential stress-radial strain loop decreases and then increases. It appears then that the radial strain component causes the differential stress-volumetric strain loops to decrease initially in size and then increase, as is seen in Figure $1 a$.

From the compressibility data of Brace [1965] it is apparent that at confining pressures as high as 9 kbar, pore closure accompanies elastic compression. For this reason the straight lines drawn coincident to some of the data in Figure 1 represent the expected volume change of the sample if the deformation were elastic. The term elastic refers to pure elastic compression and the amount of pore closure appropriate to the given confining pressure. Extrapolation of Brace's compressibility data from pressures of 5-9 kbar gave the elastic 

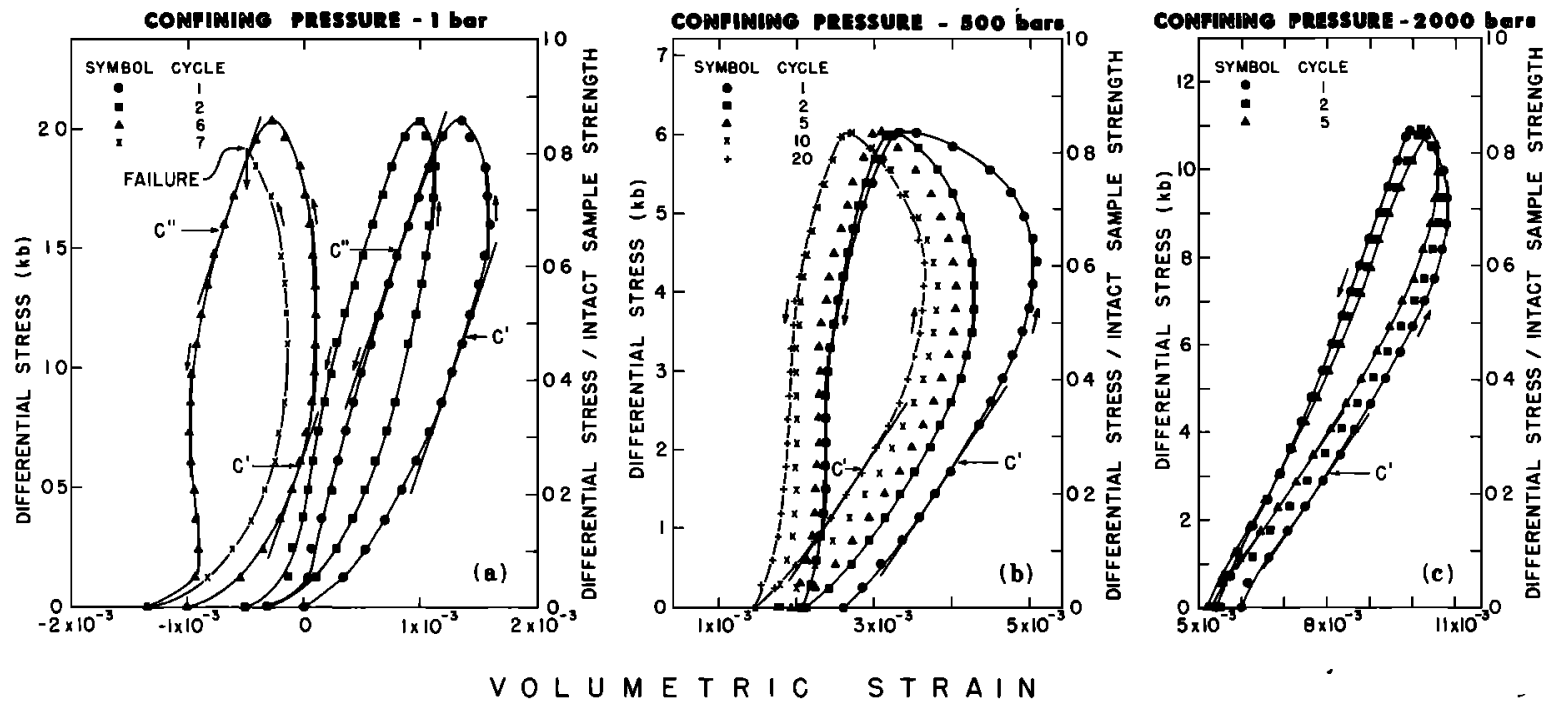

Fig. 1. Volumetric strain as a function of differential stress under $(a)$ uniaxial conditions, $(b) 500$ bars of hydrostatic confining pressure, and $(c) 2000$ bars of hydrostatic confining pressure.

lines shown. As is consistent with the nomenclature of Brace et $a l$. [1966], the onset of dilatancy is denoted by $C^{\prime}$ and with increasing axial load is defined as the stress at which the volumetric strain departs from the elastic line.

Onset of dilatancy. Virgin samples of Westerly granite contain cracks that close as an external compressive stress is applied. To illustrate the effect of these cracks on volumetric strain, Figure 2 presents the individual strain components for some of the cycles. From the pronounced toe of the axial strain component in Figure $2 a$ it is apparent that under uniaxial conditions a great deal of crack closure occurred as the sample was axially loaded. Confining pressure tends to close these random cracks, so that only a small toe is evident at 500 bars (Figure $2 b$ ) and no toe at all is evident at 2000 bars (Figure $2 c$ ). Thus as the axial load is applied to the uniaxial sample (Figure 1a), it is very difficult to identify elastic behavior and hence difficult to determine the onset of dilatancy. Since under triaxial conditions many of these random cracks are closed before application of the axial load, it is much easier to determine elastic behavior. Therefore the onset of dilatancy in Figures $1 b$ and $l c$ is fairly distinct and limited only by the resolution of the data.

Despite the difficulties under uniaxial conditions it does appear that the onset of dilatancy is reduced by the repeated cycling. In Figure $1 a$ note that between the first and sixth cycles the onset of dilatancy $\left(C^{\prime}\right)$ is reduced from about 1200 bars to about 600 bars. This is consistent with the uniaxial experiments of Scholz and Kranz [1974] and the experiments of Haimson [1974] under 70 bars of confining pressure. However, in Figures $1 b$ and $1 c$ the decrease in $C^{\prime}$ with repeated cycling under triaxial conditions is seen to be quite small. In fact, for the second through the twentieth cycles of the sample under 500 bars of confining pressure no significant change in $C^{\prime}$ was observed, nor was any significant change apparent at 2000 bars of confining pressure.

Recent work by D. Dunn (personal communication, 1974) and K. Hadley (personal communication, 1974) has also shown that $C^{\prime}$ is not affected by cycling under triaxial conditions. Dunn found no decrease in the onset of dilatancy when he cycled Catawba quartzite to $90 \%$ of its failure stress (at 250 bars of effective confining pressure). Hadley repeatedly cycled Westerly granite and San Marcos gabbro (at 5 kbar of confin- ing pressure) and also found no decrease in the onset of dilatancy.

\section{Discussion}

It is known that in an elastic body, flat cracks oriented with their major axis parallel to the direction of maximum compression mostly affect the transverse elastic strain component of that body. It appears that from the radial strain component of the uniaxial sample (Figure $2 a$ ) the transition from decreasing loop size to increasing loop size in Figure $1 a$ marks the beginning of accelerated propagation of axially oriented cracks that eventually leads to failure of the sample. In Figures $2 b$ and $2 c$ (at 500 and 2000 bars of confining pressure) no such transition in behavior is apparent, and it appears that neither triaxial sample has yet reached the stage of crack propagation that leads to sample failure. It is not known if confined samples under these pressures will eventually become unstable and fail with enough repeated cycling.

Under triaxial conditions the approach to constancy of the shape of the volumetric strain loops implies that a stable and repeatable process is occurring. Furthermore, the fact that the loops appear to approach a steady state size indicates that the amount of energy being lost into the sample per cycle approaches a constant value. To explain this behavior, the grain boundary sliding-axial crack model suggested by Brace et al. [1966] is utilized. Figure 3 illustrates this model and also the expected strains from a model such as discussed by $S$ cholz and Kranz [1974].

Simply, the model works like this: at the axial stress indicated by $C^{\prime}$ the resolved shear stress acting along some closed cracks and grain boundaries exceeds the opposing frictional stress, sliding occurs, and related cracks open and possibly extend as is shown in the figure. As the axial load is removed, backsliding of the grain boundaries and crack closure begins only after the frictional stresses can be overcome by the internal restoring forces (at the stress indicated by $\left.C^{\prime \prime}\right)$. At the end of a given cycle there can be a net increase in sample volume due to cracks that do not completely reclose, possibly because the cracks are propped open by broken off asperities.

In the triaxial experiments the trend toward constancy of the hysteresis loop size indicates that the loops progressively tend 

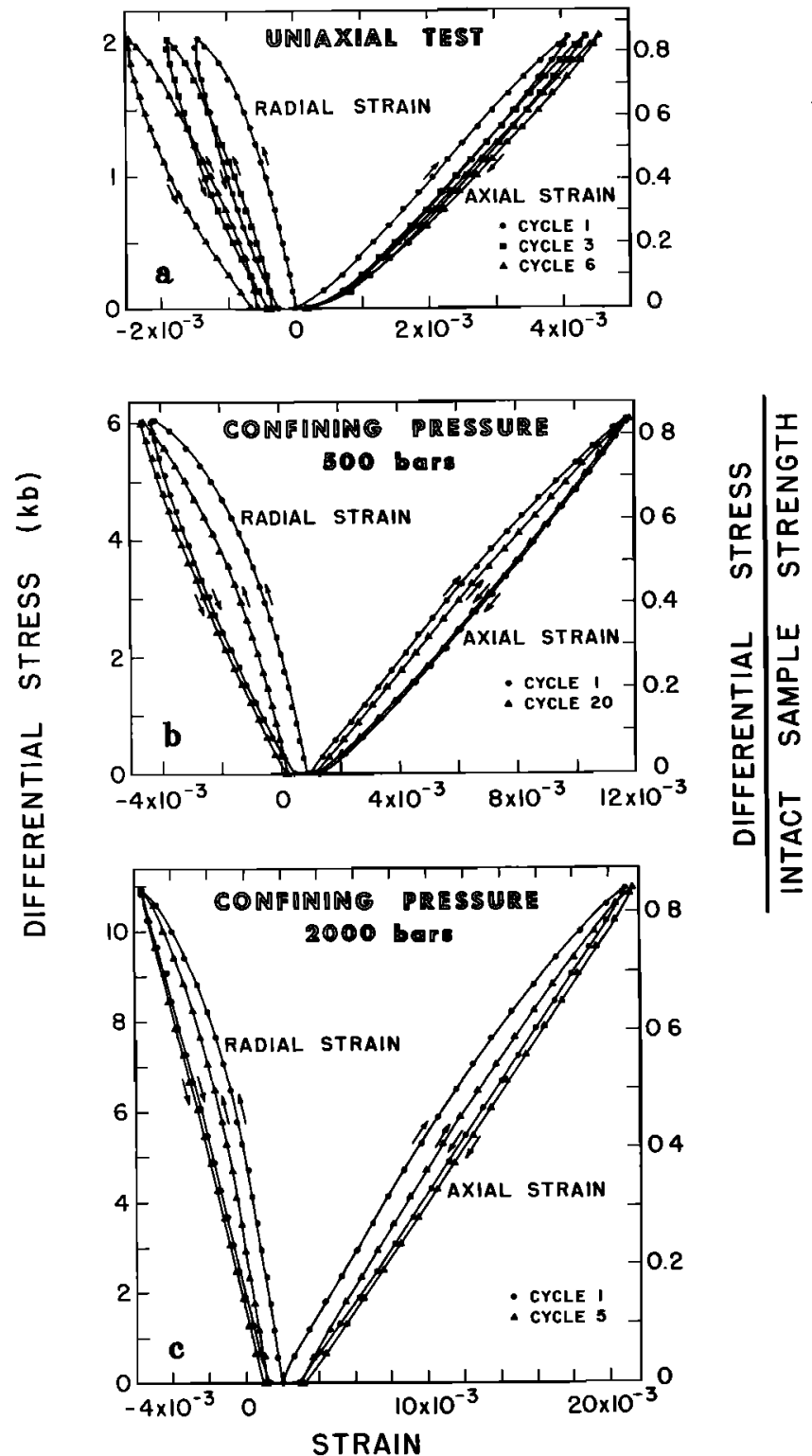

Fig. 2. Axial and radial strain as a function of differential stress under $(a)$ uniaxial conditions, $(b) 500$ bars of confining pressure, and (c) 2000 bars of confining pressure.

to represent only the amount of energy associated with grain boundary sliding, that is, frictional work. The axial cracks were stably opening and closing but with little or no crack extension. Thus the large difference between the loop size for the first cycle and that for subsequent cycles is the surface (and seismic) energy associated with crack growth during cycle 1 .

The decrease in onset of dilatancy $\left(C^{\prime}\right)$ under uniaxial conditions can possibly result from a decrease in the coefficient of grain boundary friction due to wear. Although this may be partly true, if the coefficient of friction were to be greatly decreased, one would expect a large decrease in the stress necessary to cause backsliding $\left(C^{\prime \prime}\right)$. However, the unloading parts of cycles 1 and 6 (Figure 1a) show that $C^{\prime \prime}$ is only slightly affected by the repeated cycling. Therefore a large change in the coefficient of friction does not appear to have occurred in these experiments. An alternative explanation for the reduction in $C^{\prime}$ with cycling is that the normal stress acting across the grain boundaries is reduced as the sample progressively fractures and the grains naturally loosen. Thus with little applied axial load there is little normal stress acting across the grain boundaries to oppose sliding, and the onset of dilatancy occurs at quite a low stress. It therefore appears that uniaxially, and perhaps at very low confining pressures, the onset of dilatancy depends largely on the degree to which the grains of the rock are naturally bound together.

Under triaxial conditions the constancy of $C^{\prime}$ is also quite logical. Under confining pressure, repeated sliding will change the coefficient of friction of completely interlocked surfaces very little [Byerlee, 1967], and the normal stress across the sliding surfaces will remain relatively constant. Since the frictional properties of the sliding surfaces remain relatively constant, so does the onset of dilatancy.

To determine further the validity of the grain boundary sliding-axial crack model discussed above, the following two experiments were performed.

After cycle 20 the sample at 500 bars of confining pressure was routinely loaded to the maximum differential stress but unloaded gradually as is shown in Figure 4. For the first partial cycle the sample behaved as was expected; with increasing stress the shape of the hysteresis loop is the same as that seen in Figure $1 b$, and the sample volume increased linearly as the differential stress was initially removed. However, as the differential stress was reincreased in the second partial cycle, note that some additional dilatancy occurred. This implies that either some backsliding accompanied the decrease of stress in partial cycle 1 or that some additional crack growth occurred as the stress was increased during partial cycle 2 . The subequent partial cycles behaved as expected, dilatancy occurring as the stress was increased and backsliding and crack closure accompanying the decrease in stress.

The second experiment performed to determine the validity of the grain boundary sliding-axial crack model was to observe carefully the strains which occurred when the hydrostatic pressure was sometimes removed after a given
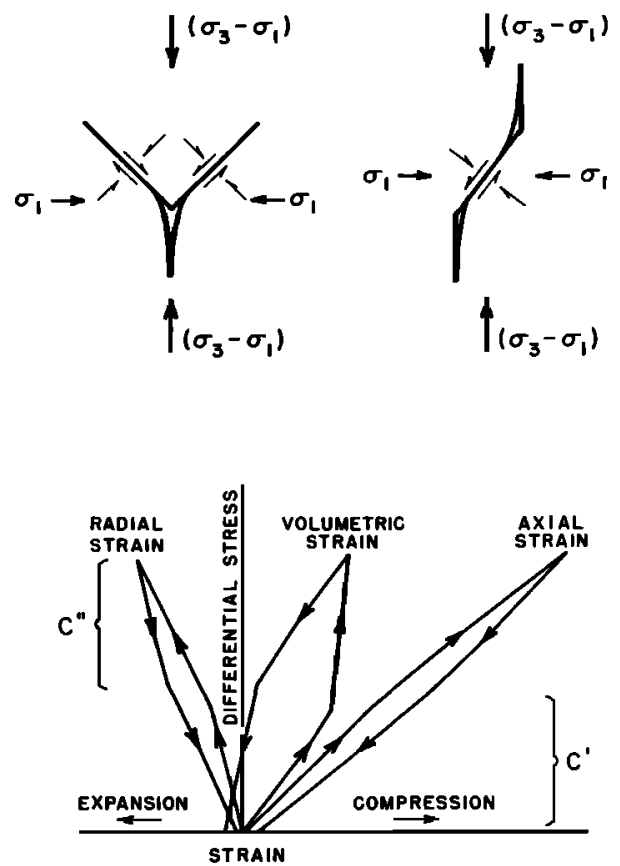

Fig. 3. (Top) A simple model for the opening of axially oriented cracks associated with sliding grain boundaries or preexisting cracks (after Brace et al. [1966]). The confining pressure and differential stress are denoted by $\sigma_{1}$ and $\sigma_{3}-\sigma_{1}$, respectively. (Bottom) The resultant strains from such a model (after Scholz and Kranz [1974]). 


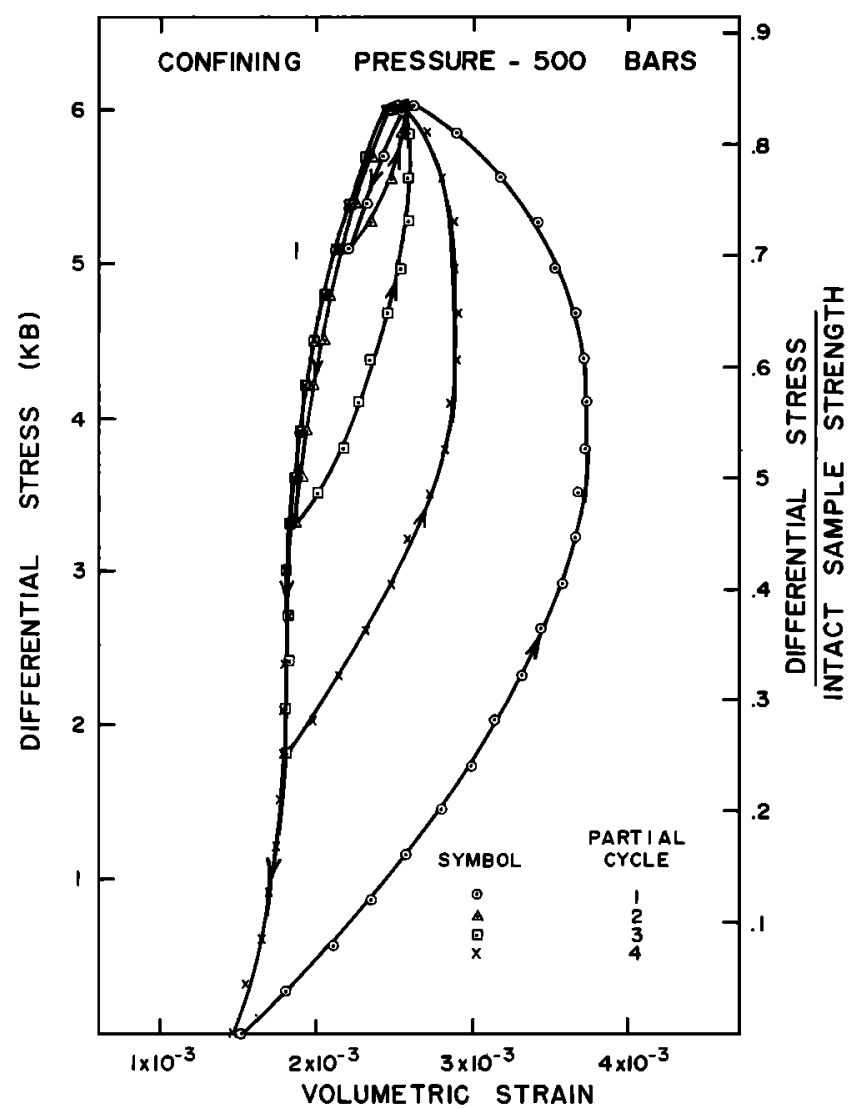

Fig. 4. Volumetric strain as a function of differential stress during gradual unloading of the sample under 500 bars of confining pressure.

differential stress cycle. A close look at the simple model presented above implies that when a sample has been completely unloaded, there cannot have been complete backsliding along the grain boundaries (and closure of the axial cracks) owing to the grain boundary friction. To illustrate this, Figure 5 shows that under 2000 bars of confining pressure, complete backsliding had not occurred when the axial load was removed and that further backsliding and crack closure occurred when the hydrostatic pressure was removed. After the first cycle of deviatoric stress (closed symbols) the sample was significantly axially compressed and radially expanded (backsliding and crack closure had not completely occurred). However, as the hydrostatic pressure was removed, the normal stress acting across grain boundaries was reduced, and backsliding and crack closure progressively took place. As the hydrostatic pressure was reincreased before differential stress cycle 2, the longitudinal strain was the same as it was before the deviatoric stress cycle, and as expected, the radial strain showed a permanent increase. This also indicates that the progressive increase in sample volume results from the axial cracks which remain open throughout the cyclic tests.

Although it is now apparent that several complex processes accompany deformation of the samples, the simple model presented in Figure 3 has proved to be quite consistent with several important features of the data. For example, the change both in the onset of dilatancy with cycling and in the size of the hysteresis loops with cycling is adequately explained by this model. Also the shape of the hysteresis loops is consistent with that of the loops of the model for the uniaxial sample. Triaxially, however, the shape of the loops is not altogether consistent with that predicted by the model. In Figure
1 this inconsistency is most apparent in the slope of the elastic portion of the cycles during unloading of the sample. The model predicted that for both loading and unloading, the elastic slopes would be the same, but triaxially this is clearly not the case. After the maximum stress had been reached and the sample had begun to be unloaded, the unloading elastic slope was significantly different from the supposedly corresponding slope for increasing stress. This behavior is also evidenced in Figures $2 b$ and $2 c$; note that there is a significant difference between the loading and unloading elastic slopes for the radial component of strain but not for the axial component.

\section{Conclusions}

The experiments reported here under 500 and 2000 bars of confining pressure have shown that dilatancy can be a stable and repeatable process, and the onset of dilatancy is essentially unaffected by repeated cycling to high compressive stress. This result is in contrast with experiments performed uniaxially (this study and that by Scholz and Kranz [1974]) and under very low confining pressure [Haimson, 1974]. Under these conditions it was found that the onset of dilatancy can be substantially reduced by repeated cycling.

The triaxial experiments reported in this study indicate that in the focal region of midcrustal earthquakes, dilatancy repeatedly occurs at a fairly high differential compressive stress, equivalent to about $25 \%$ of the failure stress in the case of Westerly granite.

The grain boundary sliding-axial crack model of Brace et al. [1966] has proved useful for conceptualizing the microscopic processes that occur during deformation of the sample. However, what appears to be a simple model in fact incorporates many complex processes. For example, time dependent

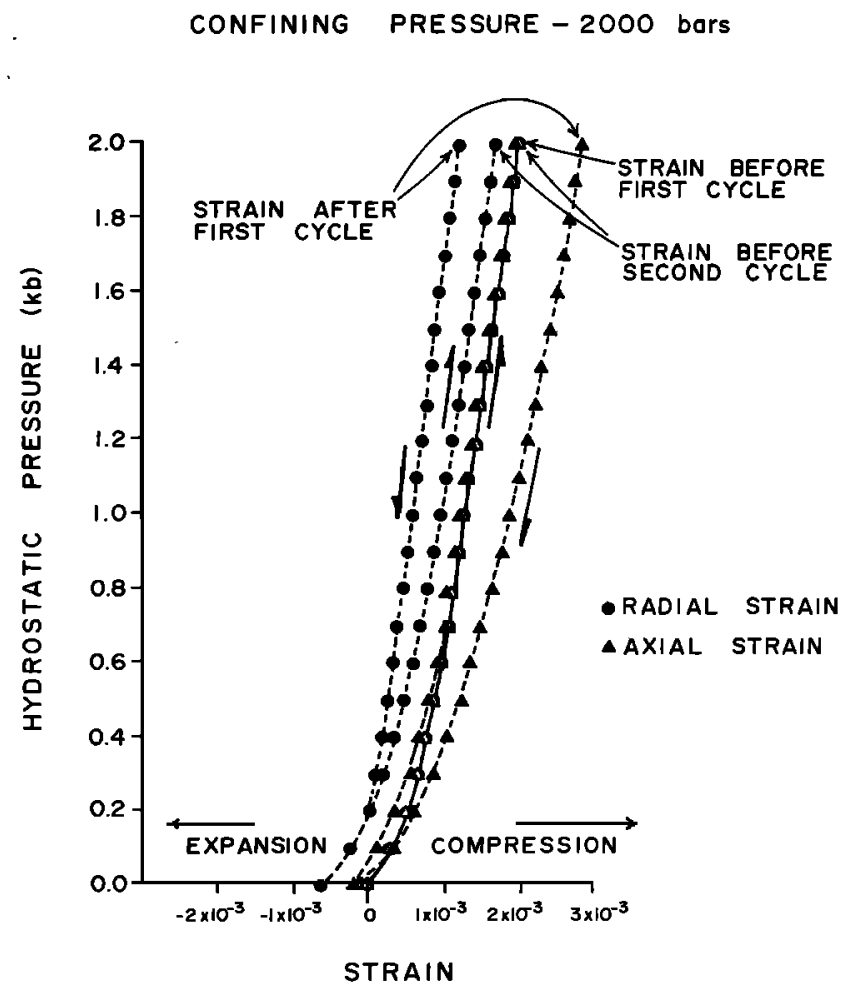

Fig. 5. Axial and radial strain as a function of hydrostatic confining pressure. The strains before the first cycle of differentual stress are indicated by the open symbols and solid line. After the first cycle the strains are indicated by the closed symbols and dashed lines. 
crack growth at high differential stress is probably quite important but is not considered in this investigation. Furthermore, under uniaxial conditions (and possibly at very low confining pressures) it is apparent that the forces that naturally bind the grains of the sample together are important in determining its dilatational characteristics.

Acknowledgments. The authors wish to thank David Dunn and Kate Hadley for making their unpublished data available to them.

\section{REFERENCES}

Brace, W. F., Some new measurements of linear compressibility of rocks, J. Geophys. Res., 70(2), 391-398, 1965.

Brace, W. F., B. W. Paulding, Jr., and C. H. Scholz, Dilatancy in the fracture of crystalline rocks, J. Geophys. Res., $7 l(16), 3939-3953$, 1966.

Byerlee, J. D., Frictional characteristics of granite under high confining pressure, J. Geophys. Res.. 72(14), 3639-3648, 1967.
Haimson, B. C., Mechanical behavior of rock under cyclic loading, in Advances in Rock Mechanics, vol. 2, part 1, National Academy of Sciences, Washington, D. C., 1974.

Mogi, K., Some precise measurements of fracture strength of rocks under uniform compressive stress, Rock Mech. Eng. Geol., 4(1), 41-55, 1966.

Nur, A., Dilatancy, pore fluids, and premonitory variations of $t_{\mathrm{g}} / t_{\mathrm{p}}$ travel times, Bull. Seismol. Soc. Amer., 62(5), 1217-1222, 1972.

Scholz, C. H., and R. Kranz, Notes on dilatancy recovery, J. Geophys. Res., 79(14), 2132-2135, 1974.

Scholz, C. H., C. R. Sykes, and Y. P. Aggarwal, Earthquake prediction: A physical basis, Science, 181, 803-810, 1973.

Zoback, M. D., and J. D. Byerlee, The effect of microcrack dilatancy on the permeability of Westerly granite, J. Geophys. Res., 80, 752$755,1975$.

(Received September 30, 1974; revised December 9, 1974; accepted December 9, 1974.) 